\title{
Estimation of Free Methylpentoses in the Presence of Glycosidically Bound Sugar ${ }^{1}$
}

\author{
A. K. BHATTACHARYYA AND D. AMINOFF \\ From the Simpson Memorial Institute, The University of Michigan, \\ Ann Arbor, Michigan
}

Received August 3, 1965

In the course of our investigations on the immunochemistry and biosynthesis of the human blood group substances, it became necessary to determine the amount of free fucose in the presence of the glycosidically bound sugar. Dische and Shettles (1) have described a specific spectrophotometric procedure for the determination of methylpentoses. This involved heating with concentrated sulfuric acid and the development of a specific color with cysteine hydrochloride. Modifications of the method have been described $(2,3)$ but in each case a strong acid is employed in the reagent. The heating with the acidic reagents releases methylpentose and converts it to the appropriate chromogen. Thus, there methods do not distinguish between free and bound methylpentoses. Indirect methods were therefore used to determine the rate of release of methylpentose under varying conditions of hydrolysis. One such method involved chromatographic separation of the sugars in the hydrolysis products followed by quantitative determination of the area corresponding to free fucose either by the cysteine- $\mathrm{H}_{2} \mathrm{SO}_{4}$ method (1) or by the Somogyi-Nelson procedure (4). Recovery of methylpentoses by these techniques was invariably low.

This paper describes a procedure which involves the oxidation of methylpentoses with periodate. Only the free methylpentose will release acetaldehyde on oxidation with periodate and thus can be determined in the presence of the glycosidically bound compound. A quantitative method for the oxidation of fucose and determination of the acetaldehyde released was previously developed by Nicolet and Shinn (5) and Cameron, et al. (6). The aeration train employed in the separation of acetaldehyde from the oxidation products is cumbersome and the procedure

\footnotetext{
${ }^{1}$ This investigation was supported in part by U. S. Public Health Service Research Grant AM 07305, National Institutes of Health, Bethesda, Md., and in part by grants from the University of Michigan Cancer Research Institute, Project \#56, National Science Foundation Institutional Grant \#32, and the University of Michigan Medical School General Research.
} 
is slow. Thus, only a few determinations can be made at a given time. This was overcome by Aminoff and Morgan (7), who adapted the procedure to Conway immunodiffusion units. A principal drawback to the general procedure has been the difficulty of titration of the aldehydebisulfite complex with iodine. In the present investigation semicarbazide hydrochloride is used to absorb the acetaldehyde. Since the resulting semicarbazone has a strong absorption in the ultraviolet (8), it can be rapidly determined spectrophometrically, thereby supplanting the more tedious titrimetric procedure. A preliminary account of this method has already appeared (9).

\section{METHODS AND RESIITTS}

Materials: Crystalline $\mathrm{L}-(-)$-fucose $\left(\mathrm{mp} 139-141^{\circ} \mathrm{C}\right)$ obtained from Pfanstiehl Laboratories Inc., Waukegan, Ill., was used as the typical methylpentuse. This was chromatographically pure in three solvent systems and had a specific rotation of $[\alpha]_{\mathrm{D}}{ }^{23}-75.9^{\circ} \pm 0.2^{\circ}$. D-Galactose, $N$-acetyl-D-glucosamine, and D-glucosamine hydrochloride were obtained from Pfanstiehl Laboratories. $N$-Acetylneuraminic acid was isolated from bovine colostrum and crystallized from methanol. The methyl glycosides of L-fucose were prepared and separated according to the procedure of Watkins (10).

Paraperiodic acid, glycine, and semicarbazide hydrochloride (Eastman Kodak Co., Rochester, N. Y.) were analytical reagents. The oxidation and absorption of acetaldehyde was carried out in modified plastic (11) Conway microdiffusion dishes (68- or 44-mm diameter) obtainable from Aloe Scientific, St. Louis, Mo. Wetting of the plastic surfaces was achieved with an aqueous solution of nonionic wetting agent NPX Tergitol supplied with the dishes. Glass or porcelain dishes can also be used, but plastic ones have been found to be more convenient.

Reagents: (a) NPX solution, $0.025 \%$ in water; $(b)$ semicarbazide hydrochloride, $0.0067 M$ in $0.06 M \mathrm{NaH}_{2} \mathrm{PO}_{4}$ and $0.14 M \mathrm{Na}_{2} \mathrm{HPO}_{4}, \mathrm{pH}$ 7.0 ; (c) periodate reagent- $0.2 M$ periodic acid, freshly prepared (1 vol), $0.2 \mathrm{~N} \mathrm{NaOH}$ (1.5 vol), $0.2 \mathrm{M}$ glycine $1.2 \mathrm{vol}$ )-prepared just before use by mixing the three solutions in the proportions indicated to obtain the optimal $\mathrm{pH}$ of $7.4-7.5$. Since sodium periodate precipitates slowly, the periodate reagent must be used within 1-2 $\mathrm{hr}$.

Procedure: The sealing chamber of the Conway unit (68-mm diameter) is filled with $0.1 \mathrm{ml}$ of NPX solution and $2.5-2.8 \mathrm{ml}$ of water. ${ }^{2}$ The sample,

${ }^{2} \mathrm{NPX}$ is not added to the inner well as it gives an appreciable absorption in the UV with the semicarbazide solution. Therefore, to cover the surface of the inner well completely, $2.5 \mathrm{ml}$ of semicarbazide solution is necessary for the $68-\mathrm{mm}$ Conway units and $0.6 \mathrm{ml}$ for the $44-\mathrm{mm}$ units. 
containing $0.05-0.2 \mu$ mole of fucose in $0.5 \mathrm{ml}$ of solution, is added to the reaction chamber followed by two drops of the NPX solution to wet the surface. Fxactly $2.5 \mathrm{ml}$ of semicarbazide hydrochloride is then added to the central chamber of the dish. Finally, $2 \mathrm{ml}$ of the periodate reagent is added to the fucose in the reaction chamber and the lid is immediately placed in position on the Conway unit. The dishes are kept at room temperature for at least $2 \mathrm{hr}$ with occasional agitation to ensure efficient mixing of the solution in the reaction mixture, and to cover completely the surface in the inner well. A reagent blank containing all the reagents with water in place of fucose is set up simultaneously. At the conclusion of the reaction, the semicarbazide solution in the inner chamber is mixed thoroughly and the optical density of the solution is read directly at 224 $m \mu$ against the reagent blank. The optical density given by the reagent blank is checked directly against the buffered semicarbazide reagent in order to determine the magnitude of the blank. Normally this does not exceed 0.050 .

The optical density obtained is directly proportional to the concentration of fucose over the range 0.01-0.5 $\mu$ mole. Where the OD is too high, the contents of the inner well can be appropriately diluted with the buffered semicarbazide reagent. The smaller Conway units, $44 \mathrm{~mm}$. can be used for the range $0.01-0.05 \mu$ mole.

Molar Extinction Coefficient: Under the conditions of assay, the molar extinction coefficient value given by fucose is $8.25 \times 10^{3}$. In the absence of glycine, the value is $8.94 \times 10^{3}$, indicating some retention of the acetaldehyde by the glycine. When, in the procedure described, known amounts of acetaldehyde are used instead of fucose in the reaction chamber, the OD obtained for the semicarbazone complex corresponds to a molar extinction coefficient of $8.18 \times 10^{3}$.

The molar extinction coefficient of crystalline acetaldehyde semicarbazone (prepared and kindly provided by E. E. Dekker, University of Michigan) in $0.2 \mathrm{M}$ phosphate buffer, $\mathrm{pH} 7$, was $12.5 \times 10^{3}$. Mixing known amounts of acetaldehyde solution with the buffered semicarbazide hydrochloride and determining the optical density directly resulted in values ranging from $11.3 \times 10^{3}$ to $12.5 \times 10^{3}$ for the "molar extinction coefficient." This value drops to $10.5 \times 10^{3}$ after $2 \mathrm{hr}$ at room temperature when in a test tube, and to $8.9 \times 10^{3}$ if kept in the inner well of the Conway unit. The decrease in optical density probably reflects the known dissociation of the acetaldehyde semicarbazone complex (8) and the resulting equilibrium in the inner and outer wells of the Conway units.

\section{Factors Affecting the Assay}

(a) Glycine as a Trapping Agent for Formaldehyde. Formaldehyde is the principal periodate oxidation product which is likely to interfere in 
the determination of acetaldehyde as the semicarbazone. Many sugars potentially present in the acid hydrolyzates of glycoproteins are likely to produce formaldehyde in the assay. Glycine was therefore added to the reaction mixture to trap this formaldehyde preferentially.

Sialic acid (NAN) is the most labile of the sugar components in glycoproteins and the most likely to be liberated under the conditions necessary to release the fucose. The efficiency of glycine as a trapping agent was therefore investigated with fucose and NAN at a ratio of $1: 5$.

The oxidation of fucose $(0.2 \mu$ mole $)$ and a mixture of fucose $(0.2$ $\mu$ mole) and NAN $(1.0 \mu$ mole $)$ was carried out in triplicate. The concentration of periodate was maintained constant and the amount of glycine varied, the appropriate adjustment of $\mathrm{pH}$ to 7.5 being achieved by the addition of varying amounts of alkali.

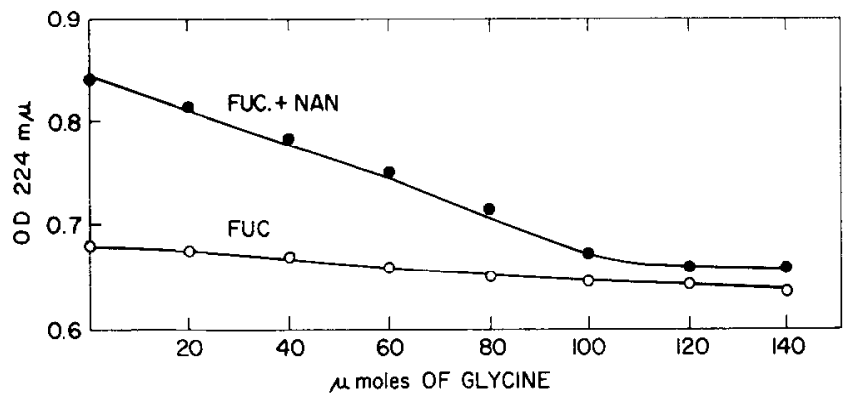

FIG. 1. Effect of amount of glycine in reaction chamber on aldehyde released on oxidation of fucose $(0.2 \mu$ mole $)$ and fucose $(0.2 \mu$ mole $)$ plus NAN (1.0 $\mu$ mole $)$.

Figure 1 shows the results obtained and indicates the importance of having the glycine well in excess $(120 \mu$ moles $)$ to trap formaldchyde effectively. At this high concentration of glycine, traces of formaldehyde still remain unabsorbed while some acetaldehyde is also trapped $(10 \%)$. The net effect is an optical density which is slightly higher (approximately $1 \%$ for an equivalent amount of NAN). Figure 2 illustrates the effect of a constant amount of NAN with varying amounts of fucose.

(b) Rate of Oxidation of Fucose. As shown in Fig. 3, at least $120 \mathrm{~min}$ is required for the complete oxidation of fucose, whether present alone or together with a 5 -fold excess of NAN.

(c) Effect of Temperature. In the standard procedure at $\mathrm{pH} 7.5$, variation of the ambient temperature from $25^{\circ}$ lo $37^{\circ} \mathrm{C}$ liad litlle or no effect on the results.

(d) Effect of $p H$. Figure 4 illustrates the effect of $\mathrm{pH}$ on the amount of aldehyde released from fucose and fucose plus NAN when oxidized with periodate for $2 \mathrm{hr}$ at room temperature in the presence of glycine. It is evident that trapping of formaldehyde by glycine is $\mathrm{pH}$-dependent. 


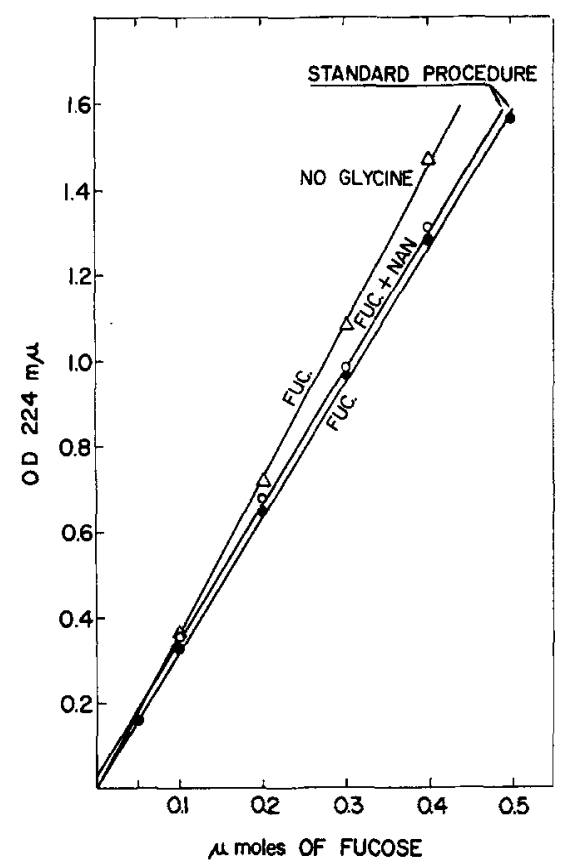

Frg. 2. Absorption curves for fucose, alone and in the presence of NAN (1.0 $\mu$ mole), in the standard procedure and in the absence of glycine.

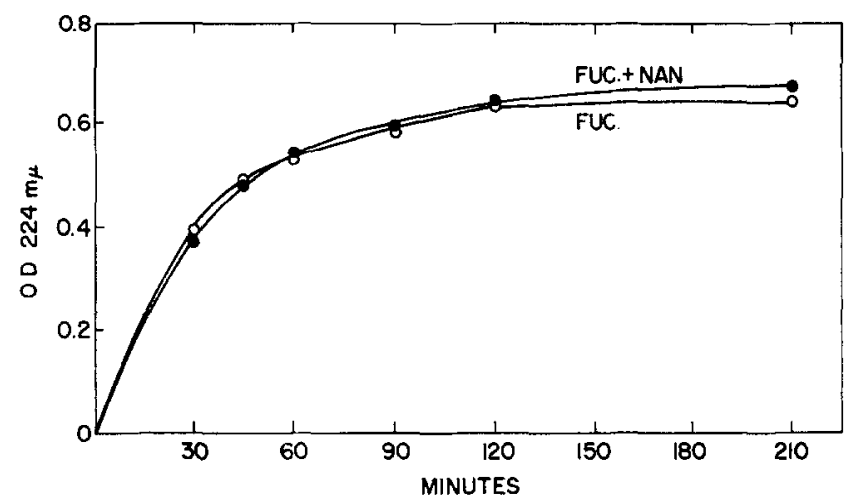

Fig. 3. Rate of release of acelaldehyde on oxidation of fucose $(0.2 \mu \mathrm{mole})$, and fucose $(0.2 \mu$ mole) plus NAN (1.0 $\mu$ mole), in the standard procedure.

Maximal acetaldehyde release with minimal interference from formaldehyde is obtained at $\mathrm{pH}$ 7.4.

(e) Concentration of Periodate. There appears to be little difference in the amount of acetaldehyde released from fucose, $0.2 \mu$ mole, with varying amounts of periodate, 25-100 $\mu$ moles. Excess periodate was considered 


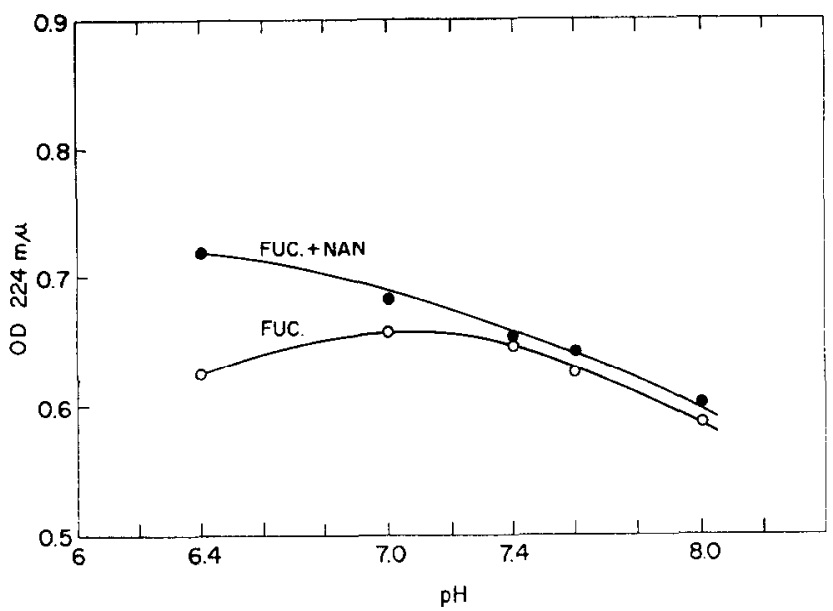

Fig. 4. Effect of $\mathrm{pH}$ on oxidation of fucose $(0.2 \mu \mathrm{mole})$, alone and in the presence of NAN $(1.0 \mu$ mole $)$, in the standard procedure.

desirable in the standard assay to allow for any extraneous oxidation of other sugars and glycoproteins in routine determinations.

\section{Specificity of Reaction}

Several sugars and nucleotides were tested (at levels of $1 \mu$ mole amounts) alone and together with fucose $(0.2 \mu$ mole $)$ to determine the extent of their interference in the assay for fucose. The determination was done in the presence and in the absence of glycine. Table 1 demon-

TABLE 1

EFFect of Interfering Substances

(percentage of acetaldehyde released from $0.2 \mu$ mole $\mathrm{L}$-fucose in presence of $1.0 \mu \mathrm{mole}$ of various compounds)

\begin{tabular}{lcc}
\hline \multicolumn{1}{c}{ Compound } & $\begin{array}{c}\text { \% } \mathrm{CH}_{3} \mathrm{CHO} \\
\text { in absence } \\
\text { of glycinc, } \\
\text { pH 7.4 }\end{array}$ & $\begin{array}{c}\text { \% } \mathrm{CH}_{8} \mathrm{CHO} \\
\text { in presence } \\
\text { of gly cine, } \\
\text { pH 7.4 }\end{array}$ \\
\hline L-Fucose & 100 & 100 \\
Sialic acid & 112 & 103 \\
D-Glucosamine & 118 & 107 \\
$N$-Acetyl-D-glucosamine & 115 & 105 \\
D-Galactose & 119 & 105 \\
Deoxyribose & 120 & 105 \\
DL-Serine & & 105 \\
Adenosine 5'-diphosphate & & 101 \\
Guanosine 5'-diphosphate & & 103 \\
Uridine 5'-diphosphate & & 99 \\
\hline
\end{tabular}


strates the effectiveness of glycine in reducing the error. A mixture of amino acids $(1 \mu$ mole of each of the following: alanine, proline, valine, lysine, leucine, tryptophan, aspartic acid, and glutamic acid) gave an optical density of 0.13 , and therefore these substances are not likely to interfere to any significant extent in the assay for methylpentoses.

\section{Reactive Compounds}

The assay is not limited to the determination of methylpentoses. Any compound capable of releasing acetaldehyde on oxidation with periodate will be detected. The results obtained with representative compounds under the conditions of the standard procedure are given in Table 2. The recovery of acetaldehyde obtained with many of the compounds in the procedure described can be improved by more prolonged oxidation (Table 2) .

TABLE 2

Recovery of Acetaldehyde from Acetaldehydogenic Compounds on Oxidation with Periodate by the Standard Procedure

\begin{tabular}{|c|c|c|}
\hline Compound & $\begin{array}{l}\mu \text { mole of } \\
\text { compound } \\
\text { oxidized }\end{array}$ & $\begin{array}{c}\% \text { recovered } \\
\mathrm{CH}_{2} \mathrm{CHO}\end{array}$ \\
\hline D-Rhamnose ${ }^{a}$ & 0.2 & 99 \\
\hline L-Rhamnose hydrate ${ }^{b}$ & 0.2 & 101 \\
\hline DL-Threonine ${ }^{c}$ & 0.2 & 99 \\
\hline $\mathrm{D}$-Fucosamine $\mathrm{HCl}^{d}$ & 0.1 & $90^{i}$ \\
\hline D-Fucosamine $\mathrm{HCle}$ & 0.1 & $84^{i}$ \\
\hline L-Fuculose-o-nitrophenylhydrazone $f$ & 0.2 & $80^{i}$ \\
\hline Colitose $^{f}$ & 0.1 & 81 \\
\hline 3-O-Methyl-L-fucose ${ }^{g}$ & 0.2 & 62 \\
\hline 2,3,4-Tri-O-methyl-L-fucose ${ }^{g}$ & 0.2 & 0 \\
\hline 5-Deoxy-L-arabinose & & \\
\hline Diethyl Dithioacetal ${ }^{h}$ & 0.2 & $86^{k}$ \\
\hline
\end{tabular}

From: (a) I. Goldstein. (b) Sigma Chemical Co., St. Louis, Mo. (c) Nutritional Biochemical Co., Cleveland, Ohio. (d) R. Wheat. (e) N. Sharon. (f) E. C. Heath. (g) G. F. Springer. (h) S. Hanessian.

${ }^{i}$ Oxidation for $4 \mathrm{hr}$ increased yield of acetaldehyde to 100 and $98 \%$, respectively.

; Oxidation for $4 \mathrm{hr}$ increased yield of acetaldehyde to $92 \%$.

k Oxidation for $4 \mathrm{hr}$ increased yield of acetaldehyde to $90 \%$.

\section{APPLICATIONS}

\section{Rate of Hydrolysis of Fucopyranosides}

Solutions of L-fucose and methyl $\alpha$-L-fucopyranoside (each containing $2 \mu \mathrm{mole} / \mathrm{ml}$ ) were hydrolyzed in small ampules for $6 \mathrm{hr}$ with $1 \mathrm{~N} \mathrm{HCl}$, $0.5 N \mathrm{HCl}$, and $1 \mathrm{~N}$ acetic acid, respectively. Each hydrolyzate was divided into two portions. One was evaported to dryness in vacuo over 
sulfuric acid and $\mathrm{NaOH}$ pellets, and reconstituted with water. The other was neutralized with $\mathrm{NaOH}$ to $\mathrm{pH}$ 7.5. The free fucose was determined in each case and expressed as a percentage of the total fucose assayed by the cysteine $-\mathrm{H}_{2} \mathrm{SO}_{4}$ procedure (1). The results are shown in Table 3 and demonstrate the low recovery of acetaldehyde obtained from hydrolyzates that were evaporated to dryness. Neutralization of hydrolyzates was, therefore, the routine procedure adopted.

TABLE 3

Stability of Fucose

(Effect of evaporation or neutralization of the hydrolyzate, $6 \mathrm{hr}$. The free fucose was determined in each case by the standard procedure described, and expressed as a percentage of the total fucose assayed by the cysteine- $\mathrm{H}_{2} \mathrm{SO}_{4}$ method.)

\begin{tabular}{|c|c|c|c|c|c|c|}
\hline \multirow[b]{2}{*}{ Compound } & \multicolumn{3}{|c|}{$\begin{array}{l}\text { Aliquot evaporated to dryness } \\
\text { and reconstituted with water }\end{array}$} & \multicolumn{3}{|c|}{$\begin{array}{c}\text { Aliquot exactly } \\
\text { neutralized with } \mathrm{NaOH}\end{array}$} \\
\hline & $1 \mathrm{~N} \mathrm{HCl}$ & $0.5 \mathrm{~N} \mathrm{HCl}$ & $\begin{array}{l}1 N \text { acetic } \\
\text { acid }\end{array}$ & $1 \mathrm{~N} \mathrm{HCl}$ & $0.5 N \mathrm{HCl}$ & $\begin{array}{l}1 N \text { acetic } \\
\text { acid }\end{array}$ \\
\hline L-Fucose & 69 & 63 & 64 & 96 & 104 & 100 \\
\hline Methyl $\beta$-L-fucopyranoside & 66 & 67 & 58 & 104 & 102 & 80 \\
\hline
\end{tabular}

The rate of release of fucose from the $\alpha$ - and $\beta$-fucosides was determined after hydrolysis with $0.1 \mathrm{~N} \mathrm{HCl}$ at $100^{\circ} \mathrm{C}$ in covered test tubes. The results are given in Figure 5 and indicate that both $\alpha$ - and $\beta$-fucopyranosides are hydrolyzed at the same rate with complete release of all the fucose in $1 \mathrm{hr}$.

\section{Rate of Hydrolysis of Fucofuranosides}

Both $\alpha$-methyl and $\beta$-methyl L-fucofuranosides are extremely labile and were completely hydrolyzed in $10 \mathrm{~min}$ with $0.1 \mathrm{~N} \mathrm{HCl}$ at $100^{\circ} \mathrm{C}$. A

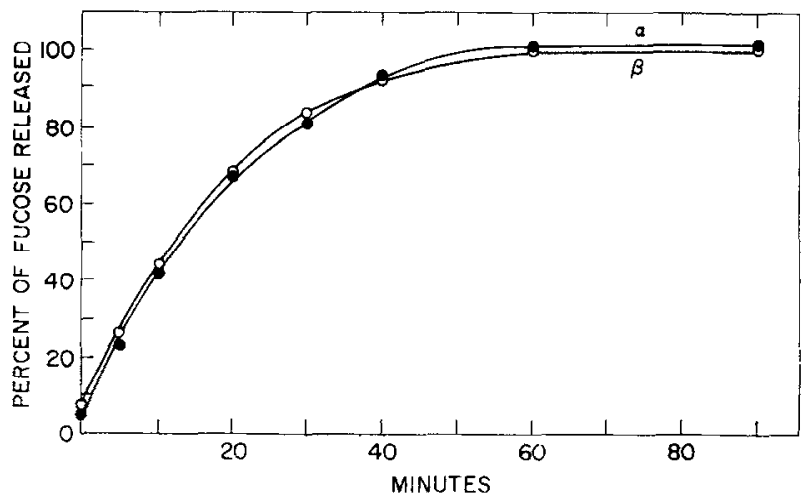

FIG. 5. Rate of hydrolysis of methyl $\alpha$ - and $\beta$-L-fucopyranosides with $0.1 \mathrm{~N} \mathrm{HCl}$ at $100^{\circ} \mathrm{C}$. 
comparison of the rate of hydrolysis of $\alpha$ - and $\beta$-furanosides was therefore made under milder conditions, at $60^{\circ} \mathrm{C}$ with $0.5 \mathrm{~N} \mathrm{HCl}$, as shown in Figure 6. It is apparent that the two glycosides show a marked difference in lability to acid: 60 min hydrolysis releases $96 \%$ of the total fucose from the $\alpha$-furanoside and only $51 \%$ from the $\beta$-derivative. Under these conditions of hydrolysis, at least $32 \mathrm{hr}$ was required for the complete release of fucose from the fucopyranosides. There was no significant difference observed in the rate of hydrolysis of the $\alpha$ - and $\beta$-fucopyranosides.

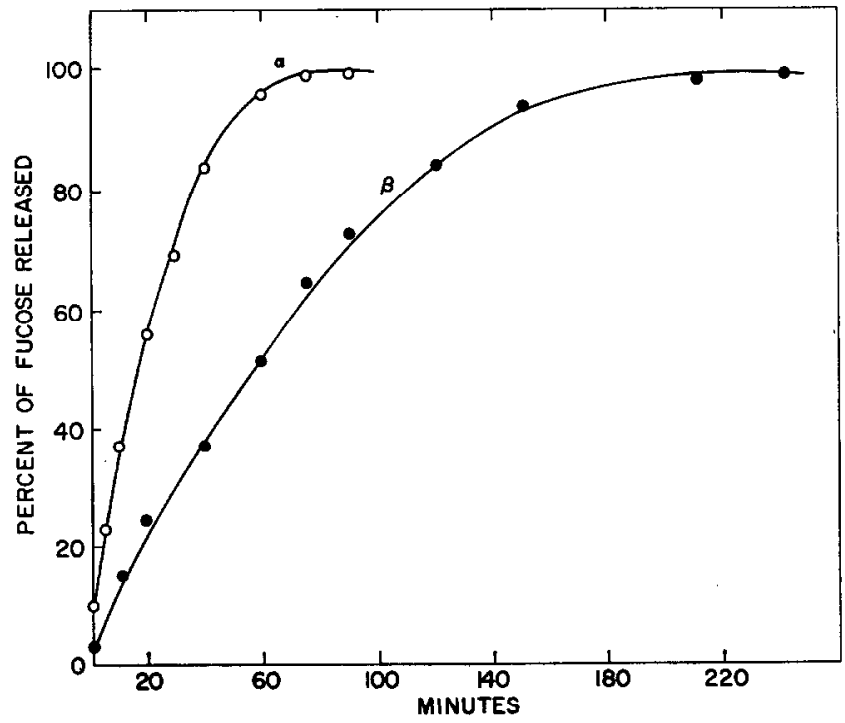

Fig. 6. Rate of hydrolysis of methyl $\alpha$ - and $\beta$-L-fucofuranosides with $0.5 \mathrm{~N} \mathrm{HCl}$ at $60^{\circ} \mathrm{C}$.

\section{Rate of Release of Fucose from Oligosaccharides}

The ready differentiation of fucopyranosides from the $\alpha$ - and $\beta$-fucofuranosides on hydrolysis for $1 \mathrm{hr}$ with $0.5 \mathrm{~N} \mathrm{HCl}$ at $60^{\circ}$ suggested the use of these conditions of hydrolysis for a comparison of the lability of different oligosaccharides and glycoproteins.

The extent of hydrolysis of $2^{\prime}$-fucosyllactose [O- $\alpha$-L-fucopyranosyl-( $1 \rightarrow$ 2) -O- $\beta$-D-galactopyranosyl- $(1 \rightarrow 4)$-D-glucose] and of lacto- $N$-fucopentaose I and II (12) is shown in Table 4. Hydrolysis is essentially complete in $16 \mathrm{hr}$. The mode of linkage of fucose in pentaose I and II differs, being $\alpha(1 \rightarrow 2)$ in the former and $\alpha(1 \rightarrow 4)$ in the latter $(12)$. The $\alpha(1 \rightarrow 4)$ linkage appears to be more labile. 
TABLE 4

Comparison of Amount of Fucose Released from a Variety of Fucose-Containing Compounds on Acid Hrdrolysis $\left(1 \mathrm{hr}\right.$ with $0.5 \mathrm{~N} \mathrm{HCl}$ at $\left.60^{\circ} \mathrm{C}\right)$

\begin{tabular}{|c|c|c|}
\hline Compound & $\begin{array}{c}\text { Total } \\
\text { fucose, } \%\end{array}$ & $\begin{array}{c}\% \text { of total } \\
\text { fucose released }\end{array}$ \\
\hline Methyl $\alpha$-L-fucopyranoside & & 19 \\
\hline Methyl $\beta$-L-fucopyranoside & & 26 \\
\hline Methyl $\alpha$-L-fucofuranoside & & 95 \\
\hline Methyl $\beta$-L-fucofuranoside & & 52 \\
\hline $2^{\prime}$-Fucosyllactose ${ }^{a}$ & & 47 \\
\hline $2^{\prime}$-Fucosyllactose ${ }^{b}$ & & 50 \\
\hline Lacto- $N$-fucopentaose $I(\alpha 1 \rightarrow 2)^{b}$ & & 32 \\
\hline Lacto- $N$-fucopentaose II $(\alpha 1 \rightarrow 4)^{b}$ & & 64 \\
\hline \multicolumn{3}{|l|}{ Glycoprotein } \\
\hline \multirow[t]{2}{*}{ with A specificityc } & Prep. I 16.3 & 36 \\
\hline & Prep. II 16.7 & 24 \\
\hline \multirow[t]{2}{*}{ with $B$ specificity ${ }^{e}$} & Prep. I 15.7 & 30 \\
\hline & Prep. II 15.5 & 28 \\
\hline \multirow[t]{2}{*}{ with $H(O)$ specificityc } & Prep. I 14.4 & 36 \\
\hline & Prep. II 15.7 & 37 \\
\hline \multirow[t]{2}{*}{ with Le ${ }^{a}$ specificity ${ }^{c}$} & Prep. I 10.8 & 59 \\
\hline & Prep. II 8.0 & 66 \\
\hline
\end{tabular}

From (a) A. P. Grollman, obtained from cow colostrum. (b) R. Kuhn, obtained from human milk. (c) W. T. J. Morgan, obtained from human ovarian cyst fluids.

Rate of Release of Fucose from Glycoproteins with Blood Group Activity

A comparison of the kinetics of hydrolysis of the glycoproteins with $\mathrm{A}$, $\mathrm{B}, \mathrm{H}(\mathrm{O})$, and Le $\mathrm{e}^{\mathrm{a}}$ specificity is shown in Fig. 7, and the extent of hydrol-

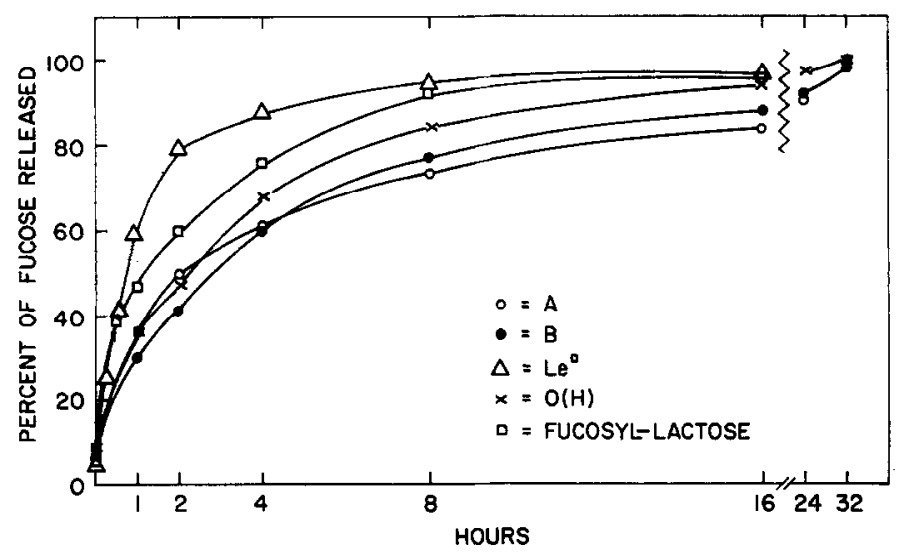

FIG. 7. Rate of hydrolysis of $\boldsymbol{2}^{\prime}$-fucosyllactose and human $\mathrm{A}, \mathrm{B}, \mathrm{H}(\mathrm{O})$, and $\mathrm{Le}^{\mathrm{a}}$ substances with $0.5 \mathrm{~N} \mathrm{HCl}$ at $60^{\circ} \mathrm{C}$. 
ysis in $1 \mathrm{hr}$ compared with that of fucose-containing oligosaccharides in Table 4.

\section{Rate of Release of Fucose from Fucoidin}

A sample of fucoidin, obtained from Dr. E. G. V. Percival, was analyzed by the cysteine-sulfuric acid method (1) and found to have a total fucose content of $53.3 \%$. All of the fucose can be released on hydrolysis for $3 \mathrm{hr}$ with $0.5 \mathrm{~N} \mathrm{HCl}$ at $100^{\circ}$. Milder conditions of hydrolysis resulted in poorer yields of acetaldehyde on oxidation as a result of either $(a)$ incomplete hydrolysis of the glycosidic bonds, or $(b)$ the substitution at $\mathrm{C}-4$ by the ethereal sulfate residues.

\section{DISCUSSION}

The entire assay procedure described here-that is, the oxidation of fucose with periodate and the absorption of the resulting acetaldehyde by semicarbazide-is essentially complete within $2 \mathrm{hr}$. In previous methods $(6-8)$ at least $5 \mathrm{hr}$ was required. Oxidation of various types of sugars will result in a variety of aldehydes. Most of these are not as volatile as acetaldehyde at room temperature and are separated by the diffusion barrier. Formaldehyde, on the other hand, can still interfere to a limited extent, and this is minimized by trapping it with glycine at the alkaline $\mathrm{pH}$ of the oxidation.

Sialic acid is the most common of the sugar components likely to be released together with methylpentoses on mild acid hydrolysis of glycoproteins. Interference resulting from sialic acid is negligible, even when present in a 5-fold excess. Although threonine is found in appreciable quantities in many glycoproteins, it is not normally released by the mild conditions of acid hydrolysis necessary to liberate the methylpentoses.

Acetaldehyde is released on oxidation of methylpentose with periodate only when the contiguous hydroxyl groups at C-4 and C-5 are free. The method can therefore be used to determine free methylpentose in the presence of the glycosidically bound furanoside or pyranoside derivatives. As such, the procedure can be used to determine the stability of the methylpentosyl-glycosidic bond to acid, alkaline, or enzymic hydrolysis.

Fucose, like other deoxy sugars, is degraded in the course of evaporation from acid solution, as is readily demonstrated by the procedure described here. It is therefore important to neutralize the hydrolysis products before analysis of the methylpentoses.

The fucosyl-glycosidic bond is very labile to acid. The $\alpha$ - and $\beta$-fucopyranosides are more stable than the corresponding furanosides. Hydrolysis with $0.5 \mathrm{~N} \mathrm{HCl}$ at $60^{\circ} \mathrm{C}$ for $1 \mathrm{hr}$ readily distinguishes between the pyranosides and furanosides, the release of fucose being $20-25 \%$ for 
pyranosides and 96 and $53 \%$ for the methyl $\alpha$ - and $\beta$-L-fucofuranosides, respectively. This marked difference in stability has been previously observed (10). A difference in the stability of $\alpha$-pyranosyl residues is also observed in different oligosaccharides.

A rapid release of fucose on acid hydrolysis of the glycoproteins with blood group activity can readily be demonstrated. The differences in the rate of release of fucose in different glycoproteins is no doubt a reflection of the type of glycosidic bond involved (13). This will be dealt with in greater detail in a subsequent communication.

\section{SUMMARY}

(1) A very sensitive method has been presented for the determination of $0.01-0.5 \mu$ moles of methylpentose.

(2) Many compounds which give rise to acetaldehyde on oxidation with periodate can be determined by this procedure.

(3) There is very little interference in this procedure from other aldehydes released on oxidation of sugars with periodate.

(4) Free methylpentose can he detected in the presence of the glycosidically bound sugar.

(5) The method has been used to determine the stability of fucose to hydrolysis and the lability of the fucosyl-glycosidic bond in furanosides, pyranosides, and a number of fucose-containing oligosaccharides and glycoproteins.

\section{REFERENCES}

1. Dische, Z., ANd Shettles, L. B., J. Biol. Chem. 175, 595 (1948).

2. Masamune, H., and Ogawa, K., Tohoku J. Exptl. Med. 60, 33 (1954).

3. Gibbons, M. N., Analyst 80, 268 (1955).

4. Nelson, N., J. Biol. Chem. 153, 375 (1944).

5. Nicolet, B. H., And Shinn, L. A., J. Am. Chem. Soc. 63, 1456 (1941).

6. Cameron, M. C., Ross, A. G., and Percival, E. G. V., J. Soc. Chem. Ind. 67, 161 (1948).

7. Aminoff, D. and Morgan, W. T. J., Biochem, J. 48, 74 (1951).

8. Burbridge, T. N., Hine, C. H., And Schick, A. F., J. Lab. Clin. Med. 35, 983 (1950).

9. Bhattacharyya, A. K., And Aminoff, D., Federation Proc. 24, 354 (1965).

10. Watkins, W. M., J. Chem. Soc. 1955, 2054.

11. Ornin r, K. J., Biochem. J. 59, 134 (1955).

12. KuHN, R., Bull. Soc. Chim. Biol. 40, 297 (1958).

13. Rege, V. P., Painter, T. J., Watkins, W. M., and Morgan, W. T. J., Nature 204, 740 (1964). 